\title{
Efficacy of working from home among urban professionals in Malaysia during the pandemic: The robust predictive role of mattering
}

\author{
Kususanto Ditto Prihadi, Edward S.Z. Lim, Kwok Chee Chan, Shirlyn M.H. Lee, Aniq Ridwan \\ Center of Cyberpsychology and Games, Department of Psychology, HELP University, Malaysia
}

\begin{tabular}{l} 
Article Info \\
\hline Article history: \\
Received Nov 11, 2020 \\
Revised Dec 3, 2020 \\
Accepted Jan 2, 2021 \\
\hline
\end{tabular}

Keywords:

Extraversion

Life Satisfaction

Mattering

Perceived Social Inclusion

Quarantine

\begin{abstract}
Past studies suggested that the sense of mattering tend to be a robust predictor of work self-efficacy, even when controlling for strong variables such as state self-esteem. This current study aimed to investigate whether the aforementioned suggested still holds among working adults who had to work from home (WFH) during the COVID-19 pandemic in Malaysia, where the government enforced movement control order (MCO), a semi-quarantine policy where individuals can only travel within 10 kilometer radius of their respective homes. We hypothesized that the state self-esteem will fully mediate the link between mattering and work self-efficacy during the period of WFH, and that trait extraversion will moderate the mediation. In the 5th week of the MCO, our data was gathered from 109 urban working adults in Malaysia who had to WFH by employing General Mattering Scale, State Self-Esteem Scale, Remote Work Self Efficacy Measure, and the extraversion facet in Big Five Inventory. The result of bootstrap analyses with 5000 samples using PROCESS Macro Model 8 suggested that state selfesteem mediated partially mediated the association of mattering and work self-efficacy among individuals at all levels of extraversion. Discussion, limitations and suggestions are provided in the end of the paper.
\end{abstract}

This is an open access article under the CC BY-SA license.

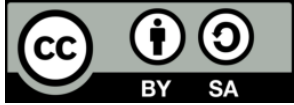

\section{Corresponding Author:}

Kususanto Ditto Prihadi

Department of Psychology

Higher Education Learning Philosophy (HELP) University

Selangor, Malaysia

Email: prihadi.k@help.edu.my

\section{INTRODUCTION}

This study aimed to investigate the mediation role of state self-esteem on the contribution of mattering on the work self-efficacy among adult employees who had to work from home during the outbreak of Coronavirus (COVID-19) in Malaysia between March and June 2020. The sudden change of the working environment (because the quarantine enforcement was conducted only in 2 days' notice) might have changed the work self-efficacy among employees, especially because of the nature of the quarantine situation that might have affected their sense of mattering and state self-esteem. Described as how employees evaluate their capacity of doing their work [1], work self-efficacy is considered important because it significantly predicts job security [2] and support at work [3]. While mattering was recently reported to be a robust predictor of work self-efficacy even after controlling for state self-esteem [4-7], this study aimed to confirm whether the results of the aforementioned studies still hold during the enforcement of working from home (WFH), where employees had to work with limited interaction with their social environment at work.

In general, mattering refers to the sense that one's matter to others, and that they perceive that they are acknowledged, important, reliable, shared emotions with, noticed when absent, appreciated, and cherished as a unique individual from the others [8]. Therefore, based on the self-efficacy theory [9], 
mattering and work self-efficacy share similar factors, which is positive reinforcement by others, or in the context of the workplace, can be obtained from social interaction with coworkers [10]. On the other hand, studies on mattering at work have yielded results that mattering can be a protective factor of stress at work [11], burnout at work [12], and the feeling that one's job is less meaningful than others' [13]; mattering was also reported to buffer the employees' attitude towards general society [6].

However, things could be different when the employees had to work from home (WFH), where they were isolated from their usual social environment in the workplace. Sociometer theory [14] explained that when individuals perceive that they are socially included, they will develop higher sense of self-esteem, which refers to the subjective feeling of being included in society or also known as state self-esteem [15]. Furthermore, it was reported that the more we feel socially included, the higher our state self-esteem will be $[16,17]$. In the context of this study the sense of mattering is associated with being socially included due to the feature of mattering, that requires acknowledgment from other individuals [8]. In other words, because one feels that they matter to others, they will develop the sense of being socially included, which leads to a higher state of self-esteem. In quarantine situation, it also implies that the sense of inclusion (state selfesteem) might explain the link between mattering and work self-efficacy. State self-esteem (SSE) is the selfevaluation that is affected by social inclusion or exclusion [18]. Conceptually, SSE is related to mattering because mattering refers to how worthy an individual thought they are in general [19]. The positive association between mattering and SSE has been established by previous current studies, which reported that when one belief that they matter, the more they will feel socially included [20,21].

Different from workers who used to work at workplaces with coworkers, individuals who used to be working remotely without direct interaction among coworkers, such as digital labor, it was reported that mattering, in the form of the belief that they and their work matter to the organization, predicts their engagement at work [22]. The link between mattering and work self-efficacy might be altered by the change from work at the office into WFH as the limitation of face-to-face contact among coworkers might also alter how the sense of mattering is developed [23-25]. Individuals who are totally quarantined during the pandemic might develop higher sense of mattering because they might be relying on social media and electronic communication to conduct their social interaction; and higher engagement in social media improves the state self-esteem [26] and mattering [27]. The quarantine situation might also alter the development of SSE among employees; first of all, when they do not go to the workplace, there will be a lower chance to experience social inclusion, such as lunch with colleagues, happy hours, and other types of impromptu social gathering, which might lead to lower SSE [15, 28, 29], for instance, it was reported that WFH leads workers to develop a sense of loneliness $[24,30,31]$ and they are more likely to feel excluded compared to on-site workers [32].

Theoretically, quarantine and WFH might affect people differently based on their individual differences. That is the reason we included trait extraversion as a moderator. Psychoanalytic theory suggested that individuals with high extraversion levels tend to seek for status and recognition [33, 34] as well as adapting to an online social environment relatively quicker than individuals with lower extraversion [35], [36], yet they still might not favor online interaction over physical ones enough to serve as a replacement medium of communication [37]. Highly extraverted individuals might miss out on important verbal and nonverbal cues which guides the flow of a physical interaction when communicating via an online social platform [38]. Furthermore, because people with relatively high extraversion tend to have higher work selfefficacy [39-42], we hypothesize that extraversion levels will interact with mattering in order to predict SSE and work self-efficacy. Supporting that, the social compensation hypothesis postulates that introverts who lack physical intimate social relationships may benefit and gain more fulfillment from online networking in the WFH situation than their working environment before WFH time [43]. The aforementioned reviews of literature led us to our hypothetical model in Figure 1.

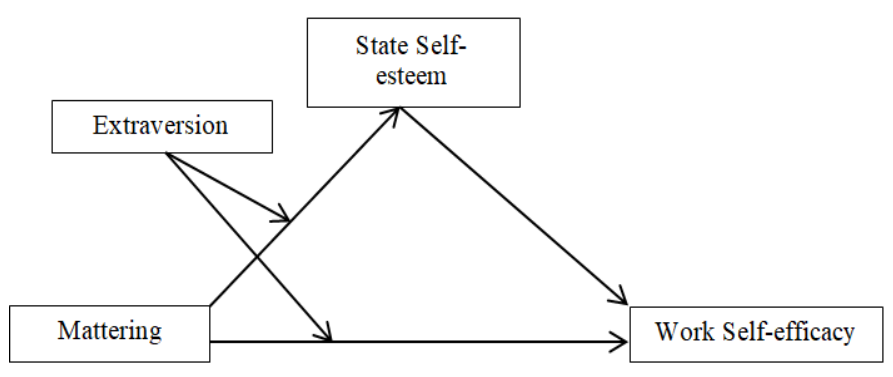

Figure 1. The hypothesized model 
In other words, we hypothesize that during the quarantine period that led the workers to WFH, state self-esteem will fully mediate the association between mattering and work self-efficacy, and extraversion will moderate the mediation, where mediation will only occur among individuals with lower levels of extraversion because they will not adapt to the quarantine social situation as fast as the ones with moderate to high levels of extraversions.

\section{RESEARCH METHOD}

This study was conducted as a survey, where a moderated mediation model was proposed. Data collection method and the scales have been approved by the ethics review board of the department of psychology HELP University Malaysia. Data was collected from 400 participants (248 female) aged between 18 and $72(\mathrm{M}=32.64, \mathrm{SD}=12.5)$, which were recruited through purposive sampling, with the inclusion criteria of being 18 years of age and above, worked from home only during the quarantine period, and not entrepreneur or self-employed. Participants were recruited via various social media platforms such as Facebook, Instagram, WhatsApp, and LinkedIn. No compensation was given as the participation of the participants was voluntary. The data was collected after they have been working from home between four and five weeks, and their participation was completely anonymous.

All materials used in this study were modified to be appropriate for the MCO context. For example, "During the MCO..." was added to supplement the material items. Basic demographic information such as age, gender, nationality, occupation was included. SSE was measured using State Self-Esteem Scale (SSES) [44], with the internal reliability of the subscales ranges from 0.73 to 0.81 [45]. Mattering was measured using General Mattering Scale (GMS) [46], with the internal reliability of the scale ranges from 0.82 to 0.92 [47]. Work self-efficacy was measured using items from the Remote Work Self Efficacy measure (RWSE) [48], with the internal validity of 0.84 [48]. Extraversion was measured using the extraversion facet in Big Five Inventory (BFI) [49].

\section{RESULTS AND DISCUSSION}

The data was analyzed by utilizing PROCESS Macro model 8 for SPSS, applying the Bootstrap analysis with 5000 samplings and $95 \%$ confidence interval. The conditional direct effect, the association between mattering and work self-efficacy at different levels of extraversion, controlling for the effect of perceived social inclusion was analyzed first, and the result is depicted in Table 1.

\begin{tabular}{|c|c|c|c|c|c|c|}
\hline Extraversion levels & Effect & se & $t$ & $\mathrm{p}$ & LLCI $^{1}$ & $\mathrm{ULCI}^{2}$ \\
\hline 20.00 & .13 & .03 & 5.07 & .00 & .08 & .18 \\
\hline 24.00 & .15 & .03 & 5.47 & .00 & .09 & .20 \\
\hline 31.00 & .18 & .04 & 4.39 & .00 & .10 & .26 \\
\hline
\end{tabular}

As shown in Table 1, when controlling for SSE, mattering significantly predicted work self-efficacy among individuals across all levels of extraversion, where the $\mathrm{p}$ value is less than 0.05 and the range between upper level and lower level of confident interval did not cross zero (both confident interval levels are positive). It indicates that extraversion levels did not moderate the direct effect of mattering on work selfefficacy. Furthermore, Table 2 depicts the test results of the moderated mediation hypothesis.

Table 2. Conditional indirect effect of mattering on work self-efficacy

\begin{tabular}{ccccc}
\hline Extraversion levels & Effect & BootSE $^{1}$ & BootLLCI $^{2}$ & BootULCI $^{3}$ \\
\hline 20.00 & .06 & .01 & .03 & .08 \\
24.00 & .06 & .01 & .04 & .08 \\
31.00 & .07 & .02 & .03 & .10 \\
\hline
\end{tabular}

${ }_{1}^{1}$ Bootstrap Standard Error Estimate
${ }^{2}$ Lower Level of Bootstrap Confident Interval
${ }^{3}$ Upper Level of Bootstrap Confident Interval

Table 2 shows that SSE significantly mediated the association between mattering and work selfefficacy at all extraversion levels, where the all the results of 5000 sampling with $95 \%$ confident interval did not show any zero (both upper and lower levels of bootstrap confident interval are positive). This result 
indicates that the moderated mediation hypothesis was not supported, because extraversion levels did not moderate the mediation. Furthermore, while SSE was a significant mediator of the link between mattering and work self-efficacy, the direct effect of mattering was significant as shown in Table 1, which means that the mediation of SSE was only partial. In other words, it can be concluded that mattering is a robust predictor of work self-efficacy, because its significance remained after being mediated by SSE, and it did not interact with extraversion levels.

Our finding that mattering significantly predicted work self-efficacy is consistent with some of the previous studies before the pandemic [4-7]. Additionally, we also discovered that SSE partially mediated the relationship between the two aforementioned variables, which means that the more the employee believed that they mattered to others, the more they feel included in the social circle, and eventually the feeling made them believe that they can perform better WFH. However, the robustness of mattering implies that without feeling socially included, employees who believed that they matter more, still tend to develop a better work self-efficacy. The interesting part of our finding is that the individual differences, in the form of extraversion levels, neither mediated the direct nor indirect effect of mattering on work self-efficacy; which means that mattering is a robust predictor of work self-efficacy among every employee who had to WFH, regardless of their extraversion levels.

That particular finding was not in line with the previous studies, which suggested that the tendency of highly extraverted individuals to adapt to online environment quicker than those with low or moderate extraversion levels $[35,36]$ or that they might still prefer to communicate directly [37]. Our finding simply indicated that regardless how extraverted the employee, as long as they believed they matter, they will also believe that they can perform well in doing their work at home. These results highlight the importance of maintaining employees' sense of mattering in order to keep their positive belief in their own work-related capabilities. In practice, Human Resource practitioners may consider integrating strategies to improve mattering among employees to buffer their workforce against any negative attitude towards work that might lead to burnout, especially during the pandemic, quarantine, and WFH. Based on the elements of mattering, efforts to keep the employees to feel acknowledged, important, missed when absent and unique are needed. Lastly, further efforts from the employers to keep the employees feel socially included is significantly suggested in order to improve their SSE, which eventually increase their work self-efficacy.

\section{CONCLUSION}

The study brought us into a conclusion that the implication of WFH policy during the pandemic will not negatively affect the workers' efficacy, as long as they believe that their presence holds significant meaning for the society, and that they feel that they are included in their social circle. WFH might physically alienated individuals and isolate them from each other; nevertheless, interrelationships among them, supported by social media activities, can always keep them believe that they matter, and therefore they will not lose their belief that they can do their work well.

Our study was not without any limitation. First of all, our findings are not capable to explain why such phenomenon occurred, especially during the quarantine period due to pandemic; therefore, further qualitative study on the subject matters is highly suggested. Second, our study did not investigate the influence of type of profession; therefore, we suggest that future research to collect more in-depth demographic data from the participants. In addition, we suggest future study to investigate the role of age in the development of work self-efficacy from mattering. Third, because we did not find that individual difference in the form of trait extraversion to be involved in the phenomenon, future research could explore the other Big Five Personalities such as conscientiousness and neuroticism, and their role as a moderator since these traits are also relevant to the work contexts. Lastly, it is also suggested for researchers of work psychology to study further on the benefits of WFH for the employees and the organizations to be implied even after the pandemic is over, hopefully soon.

\section{ACKNOWLEDGEMENTS}

This study is funded by Internal Research Grant Scheme, HELP University no. 20-07-024

\section{REFERENCES}

[1] A. K. Kirk-Brown, P. A. Van Dijk, "An empowerment model of workplace support following disclosure, for people with MS," Multiple Sclerosis Journal, vol. 20, no. 12, pp. 1624-1632, Oct. 2014, doi: 10.1177/1352458514525869.

[2] R. Sulistyawati, H. Nurtjahjanti, U. Prihatsanti, "The relationship between work efficacy and job insecurity on production employees of PT 'x' Semarang,” Empati, vol. 1, no. 1, pp. 139-153, 2018. 
[3] R. Fida, M. Paciello, C. Tramontano., et al., "Yes, I Can': the protective role of personal self-efficacy in hindering counterproductive work behavior under stressful conditions," Anxiety, Stress Coping, vol. 28, no. 5, pp. 479-499, Sep. 2015, doi: 10.1080/10615806.2014.969718.

[4] G. L. Flett, A. Khan, C. Su, "Mattering and Psychological Well-being in College and University Students: Review and Recommendations for Campus-Based Initiatives," International Journal Mental Health Addiction, vol. 17, no. 3, pp. 667-680, Jun. 2019, doi: 10.1007/s11469-019-00073-6.

[5] M. A. Karaman, A. Chandrika Kumaran, A. Haktanır, et al., "Predictors of Counselor-in-Training Students' General Self-Efficacy," Mediterr. J. Educ. Res., vol. 12, no. 25, pp. 136-149, Oct. 2018, doi: 10.29329/mjer.2018.153.8.

[6] R. J. Lamperski, "Work Namaste: The Importance of Mattering at Work, and How a Leader Can Create an Environment Where Employees Feel They and Their Work Matter," Thesis, University of Pennsylvania, Philadelphia, United States, 2018.

[7] M. E. P. Seligman, "The hope circuit: A psychologist's journey from helplessness to optimism," New York, NY: Hachette, 2018.

[8] G. L. Flett, "The psychology of mattering: Understanding the human need to be significant," Elsevier Academic Press., 2018.

[9] A. Bandura, "Encylopedia of human behavior," Academic Press, 1994.

[10] G. L. Flett, "Resilience to Interpersonal Stress: Why Mattering Matters When Building the Foundation of Mentally Healthy Schools," in Handbook of School-Based Mental Health Promotion, pp. 383-410, 2018.

[11] K. A. R. Richards, K. L. Gaudreault, A. M. Woods, "Understanding physical educators' perceptions of mattering: Validation of the Perceived Mattering Questionnaire - Physical Education," European Physical Eduction Review, vol. 23, no. 1, pp. 73-90, 2017, doi: 10.1177/1356336X16637320.

[12] J. C. Stoner, "Understanding the perceptions of mattering, feelings of burnout, and job satisfaction of resident assistants at four-year Midwestern Universities," University of Texas, 2016.

[13] K. L. Gaudreault, K. A. R. Richards, A. Mays Woods, "Initial Validation of the Physical Education Marginalization and Isolation Survey (PE-MAIS)," Measurement in Physical Education and Exercise Science., vol. 21, no. 2, pp. 69-82, 2017, doi: 10.1080/1091367X.2016.1257994.

[14] M. R. Leary, E. S. Tambor, S. K. Terdal., et al., "Self-Esteem as an Interpersonal Monitor: The Sociometer Hypothesis," Journal of Personality and Social Psychology, vol. 68, no. 3, pp. 518-530, 1995, doi: 10.1037/00223514.68.3.518.

[15] T. Pyszczynski, S. Solomon, J. Greenberg, et al., "Why do people need self-esteem? A theoretical and empirical review," Psychological Bulletin, vol. 130, no. 3. pp. 435-468, May 2004, doi: 10.1037/0033-2909.130.3.435.

[16] M. Dueñas, M. Gloria, "Pertenezco a esta Universidad? The mediating role of belonging for collective self-esteem and mattering for Latino undergraduates," Journal of College Student Development, vol. 58, no. 6, pp. 891-906, 2017, doi: 10.1353/csd.2017.007.

[17] M. J. S. Valencia, "How Online Social Media Persona Affects Personal Identity and Self," Thesis, Portland State University, 2017.

[18] E. D. Wesselmann, J. H. Wirth, M. J. Bernstein, "Expectations of social inclusion and exclusion," Frontiers in Psychology, vol. 8, p. 112, 2017.

[19] M. Rosenberg, B. C. McCullough, "Mattering: Inferred significance and mental health among adolescents," Research Community Mental Health, vol. 2, pp. 163-182, 1981.

[20] P. P. Sim, K. Prihadi, "They Logged-in, Compared, and Satisfied: Serial Mediation of Mattering and State Selfesteem on the Link between Social Comparison and Life Satisfaction," International Journal Public Health Sciences, vol. 9, no. 3, pp. 245-254, 2020, doi: 10.11591/ijphs.v9i3.20509.

[21] K. Prihadi, C. Y. Wong, K. Y. Chong, "Suicidal thoughts among University students in Malaysia and Indonesia: The role of mattering, state self-esteem and depression level," International Journal Evaluation Research Education, vol. 9, no. 3, pp. 494-502, 2020.

[22] E. Bucher, C. Fieseler, C. Lutz, "Mattering in digital labor," Journal Managerial Psychology, vol. 34, no. 4, pp. 307-324, May 2019, doi: 10.1108/JMP-06-2018-0265.

[23] S. Casale and G. L. Flett, "Interpersonally-based fears during the COVID-19 pandemic: Reflections on the fear of missing out and the fear of not mattering constructs," Clinical Neuropsychiatry, vol. 17, no. 2, pp. 88-93, 2020, doi: $10.36131 / \mathrm{CN} 20200211$

[24] M. Charalampous, C. A. Grant, C. Tramontano, E. Michailidis, "Systematically reviewing remote e-workers' wellbeing at work: a multidimensional approach,” European Journal Work Organizational Psychology, vol. 28, no. 1, pp. 51-73, Jan. 2019, doi: 10.1080/1359432X.2018.1541886.

[25] M. Tsay-Vogel, J. Shanahan, N. Signorielli, "Social media cultivating perceptions of privacy: A 5-year analysis of privacy attitudes and self-disclosure behaviors among Facebook users," New Media Social, vol. 20, no. 1, pp. 141161, Jan. 2018, doi: 10.1177/1461444816660731.

[26] S. L. Watulak, Z. Wang, S. McNary, "Facebook and Mattering: How Can Instructors Make the Most of Undergraduates' Facebook Use?," in Society for Information Technology \& Teacher Education International Conference, 2014, pp. 914-919.

[27] E. Arampatzi, M. J. Burger, N. Novik, "Social network sites, individual social capital and happiness.," Journal Happiness Studies, vol. 19, no. 1, pp. 99-122, 2018.

[28] J. B. Leitner, E. Hehman, M. P. Deegan, J. M. Jones, "Adaptive Disengagement Buffers Self-Esteem From Negative Social Feedback," Personality Social Psychology Bulletin, vol. 40, no. 11, pp. 435-450, 2014, doi: https://doi.org/10.1177/0146167214549319. 
[29] R. Hutteman, S. Nestler, J. Wagner, et al., "Wherever I may roam: Processes of self-esteem development from adolescence to emerging adulthood in the context of international student exchange," Journal of Personality and Social Psychology, vol. 108, no. 5, pp. 767-783, 2015, doi: 10.1037/pspp0000015.

[30] N. Bloom, J. Liang, J. Roberts., et al., "Does working from home work? Evidence from a chinese experiment," The Quarterly Journal of Economics.., vol. 130, no. 1, pp. 165-218, Feb. 2015, doi: 10.1093/qje/qju032.

[31] Buffer, "State of remote work," 2019.

[32] J. Grenny, D. Maxfield, "A Study of 1,100 Employees Found That Remote Workers Feel Shunned and Left Out," Harvard Business Review, Nov. 2017.

[33] R. Hogan, G. Blickle, "Socioanalytic theory," in Handbook of personality at work, N. D. Christiansen and R. P. Tett, Eds. New York: Routledge, pp. 53-70, 2013.

[34] R. Knight, "How to be good at managing both introverts and extroverts.," Harvard Business Review, Nov. 2015.

[35] S. J. Lee, "Online communication and adolescent social ties: who benefits more from internet use?," Journal Computer Communication, vol. 14, no. 3, pp. 509-531, 2009, doi: 10.1111/j.1083-6101.2009.01451.x.

[36] P. M. Valkenburg, J. Peter, "Preadolescents' and adolescents' online communication and their closeness to friends," Developmental Psychology, vol. 43, no. 2. pp. 267-277, 2007, doi: 10.1037/0012-1649.43.2.267.

[37] K. Moore, J. C. McElroy, "The influence of personality on Facebook usage, wall postings, and regret," Computers in Human Behavior., vol. 28, no. 1, pp. 267-274, 2012, doi: 10.1016/j.chb.2011.09.009.

[38] M. N. Medina, S. Srivastava, "The role of extraversion and communication methods on an individual's satisfaction with the team," Journal Organizational Psychology, vol. 16, no. 1, pp. 78-92, 2016.

[39] H. N. Perera, H. Granziera, P. McIlveen, "Profiles of teacher personality and relations with teacher self-efficacy, work engagement, and job satisfaction," Personality Individual Difference., vol. 120, pp. 171-178, Jan. 2018, doi: 10.1016/j.paid.2017.08.034.

[40] J. H. Wang, C. C. Chang, S. N. Yao, et al., "The contribution of self-efficacy to the relationship between personality traits and entrepreneurial intention," Higher Education., vol. 72, no. 2, pp. 209-224, 2016, doi: 10.1007/s10734-015-9946-y.

[41] K. Luyckx, et al., "Personal identity processes and self-esteem: Temporal sequences in high school and college students," Journal Research Personality, vol. 47, no. 2, pp. 159-170, 2013, doi: 10.1016/j.jrp.2012.10.005.

[42] R. Weidmann, T. Ledermann, A. Grob, "Big Five traits and relationship satisfaction: The mediating role of selfesteem,” J. Res. Pers., vol. 69, pp. 102-109, 2017, doi: 10.1016/j.jrp.2016.06.001.

[43] E. L. Weiqin, M. Campbell, M. Kimpton, et al., "Social Capital on Facebook," Journal Education Computer Research, vol. 54, no. 6, pp. 747-768, 2016, doi: 10.1177/0735633116631886.

[44] T. F. Heatherton, J. Polivy, "Development and validation of a scale for measuring state selfesteem," Journal Personality Social Psychology, vol. 60, pp. 895-910, 1991

[45] J. P. C. Chau, D. Thompson, A. M. Chang, et al., "Establishing the validity and reliability of the state self-esteem scale - UQ eSpace," International Stroke Conference 2008, 2009.

[46] Marcus, F. M., \& Rosenberg, M, "Mattering: its measurement and significance in everyday life. Paper presented at the annual meeting of the Eastern Sociological Society, Cincinnati, Ohio, 1987.

[47] G. Elliott, S. Kao, A.-M. Grant, "Mattering: Empirical Validation of a Social-Psychological Concept," Self Identity, vol. 3, no. 4, pp. 339-354, Oct. 2004, doi: 10.1080/13576500444000119.

[48] D. S. Staples, J. S. Hulland, and C. A. Higgins, "A Self-Efficacy Theory Explanation for the Management of Remote Workers in Virtual Organizations," Organization Sciences, vol. 10, no. 6, pp. 758-776, Dec. 1999, doi: 10.1287/orsc.10.6.758.

[49] O. P. John, S. Srivastava, "The Big Five trait taxonomy: History, measurement, and theoretical perspectives," in Handbook of personality: Theory and research, L. A. Pervin and O. P. John, Eds. New York, NY: Guilford Press, pp. 102-138, 1999. 